\title{
Assessment of Changes in the Maximum Flow of Kazakhstan Plain Rivers
}

\author{
Dinara Arystambekova ${ }^{1 *}$, Daulet Jussupbekov ${ }^{1}$, Aizhan Skakova², \\ Gulnar Kujibayeva ${ }^{3}$, Kulash Mamirova ${ }^{4}$
}

1 Department of Meteorology and Hydrology, Al-Farabi Kazakh National University, 050040, Almaty, Kazakhstan

2 Research Institute of Ecology, Al-Farabi Kazakh National University, 050040, Almaty, Kazakhstan

3 State Agency “Kazselezaschita”, 050000, Almaty, Kazakhstan

4 Department of Geography and Tourism, Kazakh National Women's Teacher Training University, 050000, Almaty, Kazakhstan

* Corresponding author's e-mail: carpediem.prof@gmail.com

\begin{abstract}
This paper presents an assessment of changes in maximum flow values (maximum discharge, $\mathrm{m}^{3} / \mathrm{s}$ ) of the spring flood caused by human activities on the rivers Zhayyk, Ilek and Tobyl. Statistical characteristics of the maximum discharge of the spring flood of these rivers for the period of 1940-2012, 1938-2012, before and after the construction of the reservoirs, as well as for the long-term period of supervision were analyzed based on the actual as well as restored data. The values of the maximum discharge of the spring flood of various provisions were calculated. The total integrated curves of the maximum discharge of the spring flood were constructed.
\end{abstract}

Keywords: maximum flow, maximum discharge, spring season, Kazakhstan, reservoirs, total integrated curve.

\section{INTRODUCTION}

For the efficient use of water resources in the future a reliable picture of the changes in the hydrological regime which had already taken place under the influence of economic activities and of the consequences which may occur due to the planned catchment event, transforming the conditions of runoff formation and climatic factors, affecting the river flow, is required (Shiklomanov, 1979).

The change of watershed hydrologic cycle has been very obvious these years because of the global climate and human activity. Dynamic binary cycle process, which includes natural and artificial water circulation, has been formed (Huang et al., 2002). Runoff is a key part of hydrological process. It directly reflects the effect of the change of area climate and human activity have on the hydrological process.
Annual runoff volume shows some certain regularity and strong randomness (Wang et al., 2002; Huang et al., 2006). Because of the dry climate and human activity, in recent years, river runoff has decreased tremendously. This caused a series of ecological environment problems, such as channel shrinkage, estuarine sedimentation, downstream river drying up, wetland degradation and loss of function of the river (Tang et al., 2012).

The main objective of the current study was to assess the impact of constructing reservoirs on the flood characteristics of Kazakhstan rivers during the spring season. The influence of reservoirs' construction was evaluated in terms of the maximum discharge of the flood during spring season for the long-term period (1940-2012) of the Zhayyk, Ilek rivers (West Kazakhstan) and Tobyl river (Northern Kazakhstan). The method of river analogy was applied. 


\section{MATERIAL AND METHODS}

The main factor in the formation of the spring floods on the rivers of the basin, as well as in other areas of the plains of Kazakhstan is a snow storage basin, the degree of soil moisture and temperature. In the steppe zone the flow of the spring flood makes $60-70 \%$ annually, in a arid and semiarid zone $-98-100 \%$.

Possessing many common natural features, the rivers of the considered basin differ in some local features, significantly and visually shown in their water regime. The surface water of the rivers of the basin is formed only during the thawing of snow cover. Thus, for example, the rivers of all three mentioned groups have the delivery prevailing snow framing the main phase of water regime - spring flood.

Spring flood (high water) on the rivers of area begins at an ice drift. On average, it comes in the first decade of April, and on the certain large rivers arteries - in the second decade of this month. The beginning of a high water ranges from the middle of March until the end of April. The main wave (peak) of spring high water on the rivers of area usually passes to the middle of April, on the larger rivers in the first pentad of May (Surface water resources, 1959).

In this paper we consider the characteristics of the spring flood of flat rivers of Kazakhstan and the effects of human activities (dam impact) on them. For the purpose of this study, three rivers and five hydrological gauging stations were selected as follows:

1. The river Zhayyk (Ural) - the Ural River, the third longest river in Europe, forms the traditional boundary between Europe and Asia. It rises in the Southeastern slopes of the Ural Mountains at $640 \mathrm{~m}$ above sea level and runs through Russia and Kazakhstan into the Caspian Sea. According to different sources, the total river length varies from 2,428 to $2,534 \mathrm{~km}$. The length of the Kazakhstan portion of the main Ural stream is $1,084 \mathrm{~km}$. The total catchment area is about $220,000 \mathrm{~km}^{2}$. The paper presents the calculations of gauging station at Zhayyk river - Kushum village. The Ural River plays a special role in the Caspian basin (Azov Bas, 2002; Lagutov, 1995), being the only freeflowing river in the region with a non-regulated hydrological regime in its lower and middle flow (Lagutov, 2008).
2. The river Ilek - the river is located in the Aktobe region of Kazakhstan and the Orenburg region of Russia. It is the largest left-bank inflow of the Zhayyk river (Ural). In this calculation, two gauging stations located on the river Ilek were selected: the Ilek river in Aktobe and the Ilek river in Shelek village.

3. The Tobyl river (Tobol) is a river in Kazakhstan and Russia. It is the left and the most highwater tributary of the river Irtysh. The river Tobyl is formed at the confluence of the Bozbey river with the Kokpektysay river on the border of the eastern spurs of the southern Ural and Turgay country. We consider two gauging stations: the Tobyl river in Pridorozhnyi village and the Tobyl river in Kostanay. It is worth to mention that all the three rivers considered in this study are transboundary.

The characteristics of the spring flow of Zhayyk, Ilek and Tobyl rivers were obtained from the data base of Leningrad Hydrological Information System of surface water and Kazakhstan Hydrometeorological services «Kazhydromet» from 1938 to 2012 year.

\section{RESULTS AND DISCUSSION}

The flow of the Zhayyk river in 1958 was disturbed by the long-term regulation of Iriklinskoe reservoir and water abstraction for the needs of different sectors of the economy (Davletgaliev, 2011). Therefore, the characteristics of the spring flow were identified for different periods - before the construction of the reservoir (1940-57 years) and after (1958-12), as well as for long-term observation period from 1940 to 2012, taking into account the recovered conditionally-natural flow value and the recovery period in 1958-12.

The flow of gauging stations of Ilek river in Aktobe and Ilek river in Shelek village in 1975 was distorted by the influence of Aktobe and Sheleksky multiyear regulation reservoirs. Regarding this, the characteristics of the spring flow were calculated for different periods - before the creation of the reservoir (1940-74 years) and after its creation (1975-12), as well as for the long-term observation period from 1940 to 2012, taking into account value of the recovered conditionally-natural flow.

The flow of gauging stations of Tobyl river in the Pridorozhnyi village in 1977 was disturbed by influence of the Verhne (Upper) Tobolsk 
reservoir and river flow of Tobyl at gauging station Kostanay was disturbed by the influence of Karatomarsk reservoir in 1965. Therefore, the spring flow characteristics were determined for different periods - before the creation of reservoirs (1938-76 and 1938-64 years) and afterwards (1977-2012 and 1965-2012), as well as for long-term observation period from 1938 to 2012, taking into account the value of recovered conditionally-natural flow.

The restoration of natural flow was made during their action with the application of the technique stated in (SP-33-101 - 2003, 2004; Arystambekova et al., 2017) for the chosen gauging stations.

The results of calculating the characteristics of the spring flow on these gauging stations can be seen in Table 1 .

The conditionally-natural flow of the Zhayyk river by the Kushum village for the period of
1958-12 was restored according to the natural annual flow of the Zhayyk river in the indicated gauging stations.

While analyzing the data given in table 1 , it is possible to assess the influence of the reservoir construction on the maximum discharge during the spring flood (maximum flow). Thus, the maximum long-term average water flow of natural period from 1940 to 1957 in Kushum village was $3950 \mathrm{~m}^{3} / \mathrm{s}$, and after the creation of the reservoir, its value decreased to $1741 \mathrm{~m}^{3} / \mathrm{s}$. The average long-term value of the maximum discharge for conditionally-natural period (1940-2012) is $3288 \mathrm{~m}^{3} / \mathrm{s}$. While comparing the value of maximum discharge for the periods of pre- (1940-57) and post-dam (1958-2012) construction, a 56\% decrease can be seen.

At river Ilek gauging stations in Aktobe, the maximum discharge of the natural period from 1940 to 1974 amounted to $735 \mathrm{~m}^{3} / \mathrm{s}$, after the

Table 1. Characteristics of maximum discharge of the spring flood $\left(\mathrm{Q}_{\text {мах }}, \mathrm{m}^{3} / \mathrm{s}\right)$

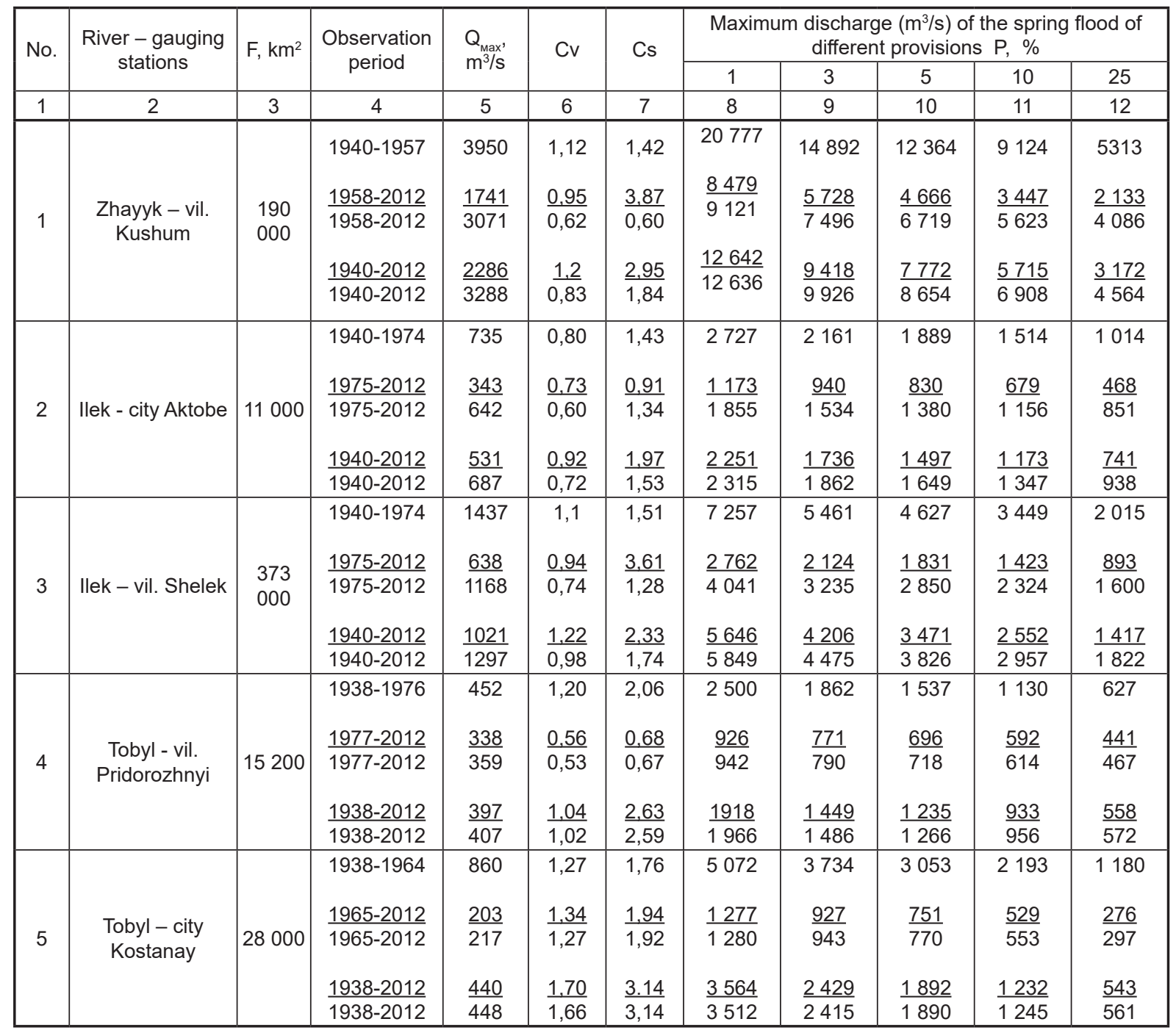


creation of the reservoir, it decreased to $343 \mathrm{~m}^{3} / \mathrm{s}$. The average long-term value of the maximum discharge for conditional natural period (19402012) equals $687 \mathrm{~m}^{3} / \mathrm{s}$. A comparison of the value of maximum discharge for the natural period (1940-74) and after the dam construction period (1975-2012) showed that the flow has decreased by $53 \%$. A similar pattern was observed in gauging station river Ilek in Shelek village. The comparison of the maximum discharge for the periods of pre-dam construction (1940-1974) amounted to $1437 \mathrm{~m}^{3} / \mathrm{s}$, and post-dam construction (19752012) showed that the maximum discharge after the dam construction has decreased to 638 $\mathrm{m}^{3} / \mathrm{s}$. The average long-term value of the maximum discharge for the conditional natural period (1940-2012) equals $1297 \mathrm{~m}^{3} / \mathrm{s}$. A comparison of the value of maximum discharge for the natural period (1940-74) and after the dam construction period (1975-2012) showed a decrease of 56\%.

The impact of water reservoirs on the maximum discharge of the Tobyl river in the Pridorozhnyi village and Kostanay city, as shown by the results of calculations (table 1), is significant as well. Thus, the gauging station of Tobyl river in Pridorozhnyi village, the maximum average annual discharge for the reservoir preconstruction period from 1938 to 1976 amounted to $452 \mathrm{~m}^{3} / \mathrm{s}$, and after the creation of the reservoir, its value decreased to $338 \mathrm{~m}^{3} / \mathrm{s}$. The average long-term value of the maximum discharge for the conditional preconstruction period (1938-2012) equals $407 \mathrm{~m}^{3} / \mathrm{s}$. A comparison of the value of maximum discharge for the natural period (1938-76) and after the dam construction period (1977-2012) shows a decrease of $25 \%$. The gauging station by the Tobyl river in Kostanay showed that the maximum average annual discharge for the natural period from 1938 to 1964 amounted to 860 $\mathrm{m}^{3} / \mathrm{s}$, and after the creation of the reservoir, its value decreased to $203 \mathrm{~m}^{3} / \mathrm{s}$. The average longterm value of the maximum discharge for the conditional natural period (1938-2012) equals 448 $\mathrm{m}^{3} / \mathrm{s}$. A comparison of the value of maximum discharge for the natural period (1938-64) and after the dam construction period (1965-2012) shows (table 1) a decrease of $76 \%$.

Table 1 also shows the values of the maximum discharge of the spring flood of various provisions. It can be observed that in all cases, the value of the maximum discharge and the runoff depth of the spring flood for the calculated periods in these towns is described as Kritsky-Menkel's curve at $\mathrm{Cs}=2 \mathrm{Cv}$.
The influence of ponds and reservoirs on a flow is considered by means of the coefficients of decrease calculated with the formula:

$$
\delta=1-W /\left(y_{h}+W\right),
$$

where: $\delta$ - coefficient of change (decrease) of flow in unit shares;

$y_{h}-$ the household drain changed under the influence of economic activity;

$W$ - volume of filling of ponds and reservoirs.

The volume of filling of ponds and reservoirs, due to the lack of regime observations of water level, is determined approximately. The coefficient of change (decrease) of an annual drain for ponds and reservoirs on the rivers $\delta$ was accepted as equal according to the recommendations of normative documents (The methodical instruction etc, 1986).

The volume of filling of ponds and reservoirs was determined by drawdown coefficient:

$$
W=K_{d r} . W_{\text {us.cap }} .
$$

where: $K_{\mathrm{dr}}-$ drawdown coefficient; $W_{\text {us.cap. }}$ - useful capacity of ponds or reser-
voirs, in one million $\mathrm{m}^{3}$.

Absolute changes (reduction) of flow were determined with the formula:

$$
\Delta y_{a v . a n .}=y_{a v . a n}(1-\delta),
$$

The natural flow was calculated using the expression:

$$
y_{\text {nat. }}=y_{\text {av.an. }}+\Delta y_{\text {av.an. }},
$$

In the presence of the observation using the graphic method - the total integral of the curve - it is possible to determine the date of commencement of anthropogenic changes and roughly estimate the changed value of the spring flow (Arystambekova et al., 2018). As an example, the graphs of the total of the integral curves of maximum discharge of the spring flood to gauging station of the river Ilek in Aktobe are presented in Figure 1.

Figure 1 shows the violation of the natural value of the maximum discharge of the spring flood of the river Ilek. The violation of spring flow began in about 1975-1976, when Aktobe and Shelek reservoirs have already operated. Comparing the data from the gauging station in Aktobe and actual value along with recovered 


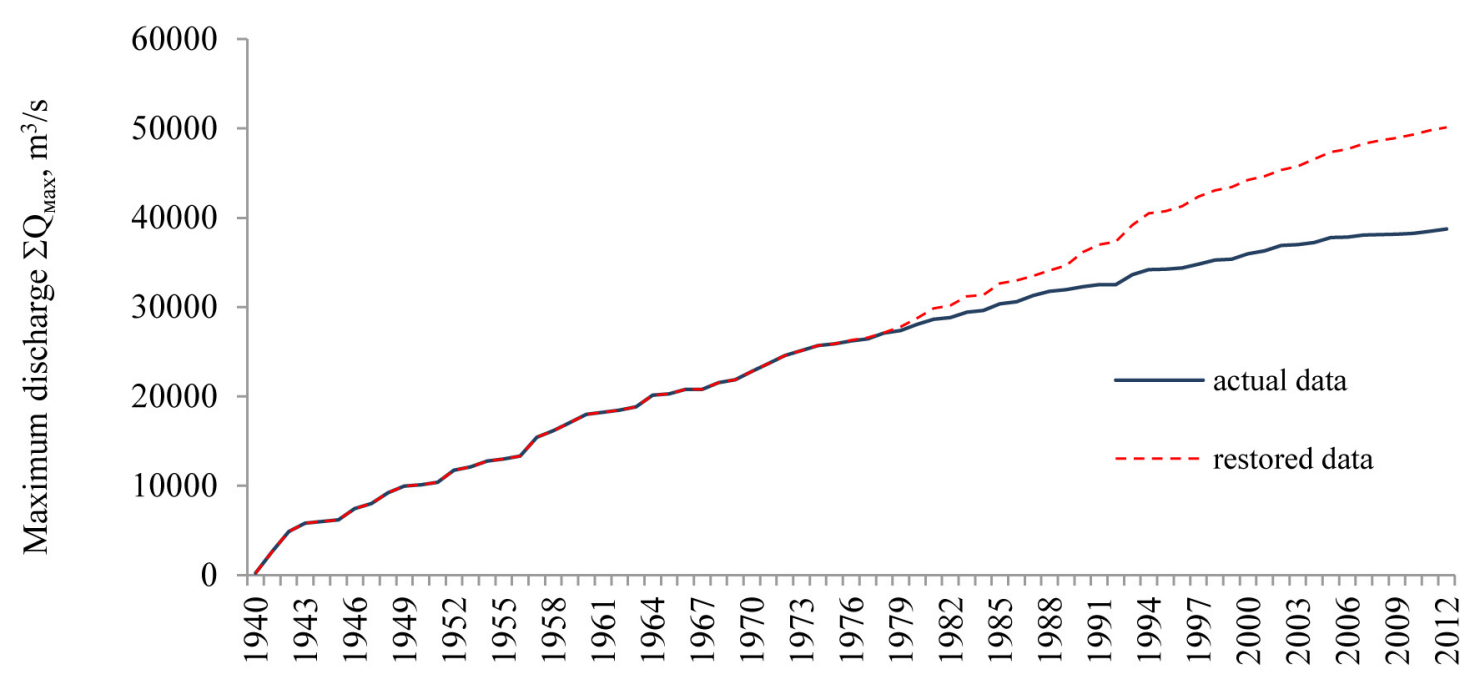

Years

Figure 1. Total integral curves of the maximum discharge $\left(Q_{\max }\right.$ $\mathrm{m}^{3} / \mathrm{s}$ ) of the spring flood of the river Ilek in Aktobe

(restored) value of the maximum discharge in 1976 , the difference amounts to $96 \mathrm{~m}^{3} / \mathrm{s}$.

\section{CONCLUSIONS}

The statistical methods stated above show significant influence of anthropogenic factors (reservoirs) on the maximum flow of the spring flood and allow us to estimate the changes of values of the maximum flow in number.

The analysis of the results shown in Table 1 helps to evaluate the effect of a significant regulating impact of reservoirs for the maximum discharge (reduction of the maximum discharge by $25-76 \%$ ).

Analyzing the characteristics of river runoff has a very important theoretical and practical meaning. It helps obtaining further knowledge of the variation trend of Surface water resources. It also provides the science evidence for rational development of water resources and protection of Ecological Environment (Tang et al., 2012).

The existing water usage regulations (in particular the management strategy for the Iriklinskoe reservoir) are extremely outdated and require significant and urgent adaptations to the current conditions. Both basin countries should participate in the development of an integrated water usage scheme which takes into account the interests of all water users. However, this issue should be approached with care considering the fact that environmental flow needs (biodiversity, self-purification, etc.) are often neglected by regional practitioners and decision-makers.

In order to secure proper consideration of environmental needs, the involvement of international organizations is required (Lagutov, 2008).

\section{REFERENCES}

1. Arystambekova D., Davletgaliev S. 2017. Impact of Reservoir Construction on Flood Characteristics of the Rivers of Kazakhstan during Spring Season. Jordan Journal of Civil Engineering, 12 (2), 314-322.

2. Arystambekova D., Davletgaliev S., Chigrinets A., Mussina A., Jussupbekov D. 2018. Estimation of Spring Runoff Characteristics of Lowland Rivers in Kazakhstan. Journal of Environmental Management and Tourism, 1 (17), 195-209.

3. Azov Bas. 2012. Proceedings. Azov Sea Basin Workshop. Green Don Publishing, Novocherkassk.

4. Davletgaliev S.K. 2011. The impact of economic activity on the annual flow of the major rivers Zhaiyk - Caspian Basin. Geography and ecology issues, 1, 4-11.

5. Huang F., Zhang S.W., De Leeuw J. 2006. 20th century, 70 years Wuyu'er Songnen Plain wetlands evolution River Basin. Natural Resources, 21 (6), 949-956.

6. Huang Q., Jiang X.H., Liu J.P. 2002. Binary mode variation of annual runoff of the Yellow River. Progress in Natural Science, 12 (8), 874-7.

7. Lagutov V. 1995. The mechanism of extermination of fish stocks in South Russia and possibilities of 
their restoration. Donskaia Rech, Novocherkassk.

8. Lagutov V. 2008. The Ural river Basin: Hydrology, Characteristics and Water Use. Springer Science \& Business Media B.V. Rescue of Sturgeon Species in the Ural River Basin, 129-161.

9. Shiklomanov I.A. 1979. Anthropogenic changes of water content of the rivers. Gidrometeoizdat, Leningrad.

10. SP-33-101-2003. 2004. Identification of the main settlement of hydrological characteristics. Gosstroi Russia, Moscow.

11. Surface water resources in areas of virgin and fallow lands, Kostanay Region of the Kazakh SSR, edition 2. 1959. Gidrometeoizdat, Leningrad.

12. Tang X. L., Li J. F., Lv X., Long H. L. 2012. Analysis of the Characteristics of Runoff in Manasi River Basin in the Past 50 Years. Procedia Environmental Sciences, 13, 1354-1362

13. The methodical instruction according to influence of economic activity on a drain of the average and big rivers and recovery of its characteristics. 1986. Gidrometeoizdat, Leningrad.

14. Wang G.X, Cheng G.D. 2002. The last 50 years in the Hexi Corridor region variation of the ecological environment and comprehensive countermeasures. Natural Resources, 17 (1), 78-86. 